\title{
DOPPLER ULTRASONOGRAPHY OF THE CENTRAL RETINAL ARTERY IN PATIENTS WITH DIABETES AND VASCULAR DISEASE TREATED WITH TOPICAL TIMOLOL
}

\author{
ROBERT D. STEIGERWALT JR ${ }^{1,2}$, GIANNI BELCARO ${ }^{1,3}$, MARIA ROSARIA CESARONE ${ }^{1}$, \\ GIUSEPPE LAURORA ${ }^{1}$, MARIA DE SANCTIS ${ }^{1}$, LUCREZIA INCANDELA $^{1}$ and \\ VICKY CHRISTOPOULOS ${ }^{3}$ \\ Pescara and Rome, Italy and London
}

\begin{abstract}
SUMMARY
Using high-resolution duplex scanning it is possible to evaluate the blood flow velocity in the central retinal artery of the eye. Four different patient groups were studied with this technique: normals, diabetics with a decreased flow, diabetics with an increased flow and vascular patients with a decreased flow. The eyes of these patients were then treated with topical timolol and the flow measured again. An increase in the flow was found in three of the four groups. This increased flow velocity may be due to a vasodilatory effect of timolol. The results are presented and discussed.
\end{abstract}

Timolol maleate is a topical medication extensively used in ophthalmology to lower the intraocular pressure (IOP) in patients with glaucoma. ${ }^{1-5}$ It is a non-selective beta-adrenergic receptor blocking agent, the hypotensive effect of which has been extensively studied and found to be through a decrease in the rate of aqueous humour formation by the ciliary body. ${ }^{6}$ The effect of topical timolol on the retinal circulation has been studied. Grunwald studied the retinal venous circulation as it was influenced by topical timolol maleate $0.5 \%$ utilising a laser Doppler. He found a significant increase in the venous blood flow in normal volunteers ${ }^{7}$ and in ocular hypertensives. ${ }^{8}$ The blood flow velocity in the central retinal artery (CRA) of normal human

From: ${ }^{1}$ Angiology and Vascular Surgery Centre, Hypertension Section, Pierangeli Clinic, Pescara, Italy; ${ }^{2}$ ARS Medica Clinic, Rome, Italy; ${ }^{3}$ Irvine Cardiovascular Laboratory for Investigation and Research, Academy Surgical Unit, St Mary's Hospital Medical School, London, UK.

Correspondence to: Robert D. Steigerwalt Jr, MD, Casa di Cura Pierangeli, Piazza L. Pierangeli 1, I-65100 Pescara, Italy. Fax: 06-36208502. volunteers treated with topical timolol maleate $0.5 \%$ has also been studied. Using the duplex scanner a significant increase was found in the blood flow velocity of the CRA, with a $43.58 \%$ increase in the systolic phase and a $61.53 \%$ increase in the diastolic phase. There was also an increase in the diastolic component (D.Comp.) from $49.29 \%$ to $55.56 \%$, indicating a decrease in the peripheral vascular resistance. ${ }^{9,10}$

The duplex scanner has also been used to study the blood flow velocity in the CRA of patients with vascular disease in the form of diabetes or peripheral vascular disease. Alterations in the flow velocities were found in both cases. In patients with cerebrovascular or peripheral vascular disease, a decrease was found in the flow velocity of the CRA when compared with the flow in normals. ${ }^{11}$ In the case of patients with diabetes the flow velocity of the CRA may be normal at the beginning of the disease, elevated in the intermediate stages and decreased in the more advanced stages of the disease when compared with the flow in normals. Since patients under treatment with topical timolol for glaucoma frequently have these associated diseases it would be important to know what effect topical timolol had on the flow velocity of the CRA when these vascular problems are also present. The aim of this study was to evaluate the effect of topical timolol maleate $0.5 \%$ on the flow velocity of the CRA in the eyes of patients with diabetes or peripheral and/or cerebrovascular disease. We present our results using the duplex scanner for the flow measurements.

\section{MATERIALS AND METHODS}

In this study we used a high-resolution ATL 
Ultramark 4 duplex scanner (Advanced Technology Laboratories, Bothell, Washington, USA) with a variable focus $5,7.5,10 \mathrm{MHz}$ access probe with remote control. A nominal imaging frequency of 10 $\mathrm{MHz}$, a transmitted Doppler frequency of $5 \mathrm{MHz}$ and a wall filter setting of $200 \mathrm{~Hz}$ were used in each measurement.

The nature of the experiment was fully explained to each of the patients and informed consent was obtained before beginning. The patient was examined while lying on his or her back on the examining table. Our technique to measure the blood flow velocity of the CRA has been described previously. ${ }^{10,11}$ One eye was selected from each of the patients and the peak systolic flow velocity (PSFV) and end-diastolic flow velocity (EDFV) of the CRA as it exits from the optic nerve head were measured. The carotid flow velocity was also recorded on the same side as the eye selected to be studied in our normals, to ensure that haemodynamically significant lesions were not present that could alter the ocular measurements. In the case of patients with diabetes or vascular disease, we also took measurements of the flow of the carotid and peripheral vessels to evaluate the presence and extent of their disease. Following the initial eye measurements a drop of timolol maleate $0.5 \%$ was instilled in the eye to be studied, followed by a second drop 5 minutes later. After 30-45 minutes the PSFV and the EDFV in the CRA were again measured and recorded in that eye. The diastolic component [D.Comp. $=\mathrm{EDFV} /(\mathrm{PSFV} /$ 100)] was calculated for the flow velocity before and after topical timolol.

The Mann-Whitney $U$-test was used for statistical analysis.

The patients were divided into four groups. The first consisted of our control group of healthy white volunteers. The second group was patients with cerebrovascular or peripheral vascular disease who had a decrease in the blood flow velocity of the CRA. The third group was insulin-dependent diabetic patients who had peripheral diabetic microangiopathy detected by laser Doppler flowmetry. ${ }^{12,13}$ The diabetics were further divided into two subgroups according to the blood flow velocity of the CRA: subgroup $A$ had an increase in the flow velocity of the CRA and subgroup B had a decrease in the flow velocity of the CRA. The eye flow studies were done together with the peripheral flow evaluations. In the case of hypertensive patients, there was a washout period in which the patients were off their medication before the study. Patients on cardiovascular medication were also excluded. The pupils of the eyes were not dilated during the flow measurements to avoid any effect the mydriatic drops could have on the retinal blood. After the administration of timolol drops we also monitored the peripheral microcirculation of all the patients to evaluate possible systemic microcirculatory effects of timolol. Patients were excluded if they had severe cardiac disease, if there was renal impairment, if a neoplasm was present or if they had other major systemic disease.

\section{RESULTS}

General information about the three groups is presented in Table I, indicating the number of patients, their age, blood pressure and the duration of their disease.

The first group consisted of 12 healthy white volunteers. There was no history of ocular or systemic disease and all had normal eye examinations with a best refracted visual acuity of 20/20 (6/6) or better. The intraocular pressure was $21 \mathrm{mmHg}$ or less and the anterior segment and fundus examinations were normal. None were known diabetics, none had known circulatory problems and none were taking systemic or ocular medication. The mean age was 45.7 years (SD 9). In these patients the mean brachial systolic pressure was $118.7 \mathrm{mmHg}$ (SD 13) and the mean diastolic pressure was $71.4 \mathrm{mmHg}$ (SD 9). After the administration of topical timolol maleate $0.5 \%$ there was an increase in the blood flow velocity of the CRA in all the eyes. The PSFV increased from $22.1 \mathrm{~cm} / \mathrm{s}$ (SD 4) to $26.5 \mathrm{~cm} / \mathrm{s}$ (SD 6) $(p<0.01)$. The EDFV increased from $10.3 \mathrm{~cm} / \mathrm{s}$ (SD $3)$ to $13.5 \mathrm{~cm} / \mathrm{s}(\mathrm{SD} 4)(p<0.05)$. The D.Comp. increased also, from $46.60 \%$ to $58.49 \% \quad(p<0.05)$ (Table II).

The second group consisted of 23 patients with either central or peripheral vascular problems as documented by us with duplex scanning and/or CT scanning. The ocular examinations were normal with intraocular pressures of $21 \mathrm{mmHg}$ or less. The patients with previous ocular surgery or ocular disease such as glaucoma or uveitis were excluded. None were taking ocular medication. These patients were seen in our vascular centres and all had a decrease in the flow velocity of the CRA when compared with that in our normals. There was an

Table I. General information about the patient groups

\begin{tabular}{llclc}
\hline & Age (years) & No. & Blood pressure (mmHg) & Duration of disease (years) \\
\hline Group 1 & 45.7 (SD 9) & 12 & $118.7 / 71.4$ (SD 13 and 9) & 0 \\
Group 2 & 59.7 (SD 9) & 23 & $146.7 / 94.6$ (SD 16 and 9) & Unknown \\
Group 3 & 56.6 (SD 9) & 43 & $139.3 / 87.0$ (SD 18 and 8) & 6.7 (SD 5) \\
Subgroup A & & 23 & & 13.5 (SD 7) \\
Subgroup B & & 20 & & \\
\hline
\end{tabular}


Table II. Variation in the blood flow velocity $(\mathrm{cm} / \mathrm{s})$ after two drops of topical timolol maleate $0.5 \%$ in the eyes of normals

\begin{tabular}{|c|c|c|c|c|c|}
\hline & \multicolumn{2}{|c|}{ PSFV } & \multicolumn{2}{|c|}{ EDFV } & \multirow[b]{2}{*}{ D.Comp. } \\
\hline & Mean & SD & Mean & SD & \\
\hline Before timolol & 22.1 & $\begin{array}{l}4 \\
6 * *\end{array}$ & 10.3 & $\begin{array}{l}3 \\
4 *\end{array}$ & $\begin{array}{l}46.60 \% \\
5849 \% *\end{array}$ \\
\hline
\end{tabular}

PSFV, peak systolic flow velocity; EDFV, end-diastolic flow velocity; D.Comp., diastolic component = EDFV/(PSFV/100). ${ }^{*} p<0.05 ;{ }^{* *} p<0.01$.

increase in the flow velocity after topical timolol maleate $0.5 \%$ but it was less than that seen in the normals. Their mean age was 59.7 years (SD 9) and there was a moderate increase in the brachial blood pressure with a mean of $146.7 / 94.6 \mathrm{mmHg}(\mathrm{SD} 16$ and 9). The PSFV was $16.8 \mathrm{~cm} / \mathrm{s}$ (SD 7), significantly slower than that in the normals $(p<0.01)$, and it increased after topical timolol to $20.7 \mathrm{~cm} / \mathrm{s}$ (SD 9) $(p<0.01)$. The EDFV was $7.1 \mathrm{~cm} / \mathrm{s}$ (SD 6), again significantly reduced when compared with that of the normals $(p<0.05)$, and increased after topical timolol to $10.3 \mathrm{~cm} / \mathrm{s}(\mathrm{SD} 6)(p<0.05)$. The D.Comp. before timolol of $42.26 \%$, which was significantly reduced when compared with that of the normals $(p<0.05 \%)$, increased after topical timolol to $49.75 \%(p<0.01)$ (Table III). Three other vascular patients were seen by us who had no increase in the flow of the CRA after topical timolol. All 3 had an internal carotid occlusion.

The third group consisted of 43 insulin-dependent diabetics with a mean age of 56.6 years (SD 9). These patients had intraocular pressures of $21 \mathrm{mmHg}$ or less and none had glaucoma or previous ocular surgery. Their fundus examinations were either normal or showed mild background diabetic retinopathy (BDR). Patients with diabetic macular oedema (DMO), preproliferative diabetic retinopathy or proliferative diabetic retinopathy (PDR) were excluded. These patients had peripheral diabetic microangiopathy as detected by laser Doppler flowmetry and could be divided into two subgroups according to their blood flow characteristics. Subgroup A consisted of 23 patients with an increase in the flow velocity of the CRA when compared with the flow in normals. Subgroup B consisted of 20 patients who had a decrease in the flow velocity of the CRA with both the systolic and diastolic phases of flow being decreased. The patients in subgroup A were diabetics of moderate duration with a mean disease duration of 6.7 years (SD 5) and with intermediate phases of microvascular complications. They had significantly altered laser Doppler parameters of the peripheral and distal (foot) circulation with an increased resting blood flow (RBF) in the skin of the feet and a decreased venoarteriolar reflex. ${ }^{12,13}$ These patients were without severe neuropathy as shown by electromyography and without large vessel disease. The patients in subgroup $B$ were diabetics of longer standing with a mean disease duration of 13.5 years (SD 7) who had more severe and long-standing microangiopathy with more severe microvascular peripheral alterations on laser Doppler flowmetry. They all had a decrease in the blood pressure (Doppler ultrasonography) in the skin of the feet. These diabetics with longer-standing disease tended to have claudication (12 of 20), large vessel disease and skin ulceration ( 7 of 20 ) in addition to the marked alterations in their microcirculatory skin flux. ${ }^{14}$

These characteristics of the two subgroups paralleled the flow characteristics that were measured in the eye. In subgroup A the flow velocity of the CRA was significantly increased when compared with that of normals. The PSFV was $29.7 \mathrm{~cm} / \mathrm{s}$ (SD 11), significantly higher than that in the normals $(p<0.01)$, and the change after topical timolol was not significant (Table IV). The EDFV was $18.7 \mathrm{~cm} / \mathrm{s}$ (SD 9), significantly increased when compared with that of the normals $(p<0.01)$, and the change after topical timolol was also not significant (Table IV). The change in the D.Comp. for this subgroup was also not significant. In subgroup B the flow velocity of the CRA was significantly decreased when compared with that of the normals. The PSFV was $14.6 \mathrm{~cm} / \mathrm{s}$ (SD 4), significantly decreased when compared with that of the normals $(p<0.01)$, and

Table III. Variation in the blood flow velocity $(\mathrm{cm} / \mathrm{s})$ after two drops of topical timolol maleate $0.5 \%$ in 23 patients with peripheral and/or cerebrovascular disease

\begin{tabular}{|c|c|c|c|c|c|}
\hline & \multicolumn{2}{|c|}{ PSFV } & \multicolumn{2}{|c|}{ EDFV } & \multirow[b]{2}{*}{ D.Comp. } \\
\hline & Mean & SD & Mean & SD & \\
\hline Normal values & 22.1 & 4 & 10.3 & 3 & $46.6 \%$ \\
\hline Patients before timolol & 16.8 & $7 \dagger \dagger$ & 7.1 & $6 \dagger$ & $42.26 \% \dagger$ \\
\hline Patients after timolol & 20.7 & $9 * *$ & 10.3 & $6^{*}$ & $49.75 \% * *$ \\
\hline
\end{tabular}

PSFV, peak systolic flow velocity; EDFV, end-diastolic flow velocity; D.Comp., diastolic component = EDFV/(PSFV/100).

${ }^{*} p<0.05,{ }^{*} p<0.01 ; p$ values indicate differences between before and after timolol. $\dagger p<0.05, \dagger \dagger p<0.01 ; p$ values indicate differences from the normals. 
Table IV. Variation in the blood flow velocity $(\mathrm{cm} / \mathrm{s})$ after two drops of topical timolol maleate $0.5 \%$ in 43 patients with diabetes

\begin{tabular}{|c|c|c|c|c|c|}
\hline & \multicolumn{2}{|c|}{ PSFV } & \multicolumn{2}{|c|}{ EDFV } & \multirow[b]{2}{*}{ D.Comp. } \\
\hline & Mean & SD & Mean & SD & \\
\hline Normal values & 22.1 & 4 & 10.3 & 3 & $46.6 \%$ \\
\hline \multicolumn{6}{|l|}{ Diabetics in group A } \\
\hline Before timolol & 29.7 & $11 \dagger \dagger$ & 18.7 & $9+\dagger$ & $62.96 \%+\dagger$ \\
\hline After timolol & 29.3 & $10 \mathrm{NS}$ & 19 & $8 \mathrm{NS}$ & $64.84 \%$ NS \\
\hline \multicolumn{6}{|l|}{ Diabetics in group B } \\
\hline Before timolol & 14.6 & $4 \dagger \dagger$ & 4.1 & $8+\dagger$ & $28.08 \%+\dagger$ \\
\hline After timolol & 19.4 & $6^{*}$ & 7 & $6^{*}$ & $30.92 \% *$ \\
\hline
\end{tabular}

PSFV, peak systolic flow velocity; EDFV, end-diastolic flow velocity; D.Comp., diastolic component = EDFV/(PSFV/100).

${ }^{*} p<0.05,{ }^{*} p<0.01 ; p$ values indicate differences between before and after timolol. $\dagger p<0.05, \dagger \dagger p<0.01 ; p$ values indicate differences from the normals.

the increase after topical timolol to $19.4 \mathrm{~cm} / \mathrm{s}(\mathrm{SD} 6)$ was significant $(p<0.05)$, but the flow velocity was still less than that seen in the normals. In this group the EDFV was $4.1 \mathrm{~cm} / \mathrm{s}$ (SD 8), significantly decreased when compared with the normals $(p<0.01)$, and this increased to $7.0 \mathrm{~cm} / \mathrm{s}$ (SD 6) after topical timolol. This increase was significant $(p<0.05)$, but the flow velocity was still less than that in normals after timolol (Table IV). In this group the D.Comp. was less than that in the normals but did increase after timolol (Table IV). In all 20 patients in subgroup B there was a significant asymmetry of the flow velocity in the CRA of more than $30 \%$ in the PSFV between the two eyes in the same patient. The asymmetry of the blood flow velocity was significantly reduced but still present in 16 of 20 patients after the administration of timolol. During the study we also monitored the peripheral skin flux by laser Doppler flowmetry in all three groups of patients before and after the administration of the topical timolol. We found no significant quantitative or qualitative changes, indicating that there are no significant effects on the peripheral microcirculation after topical timolol.

\section{DISCUSSION}

The purpose of this study was to evaluate the findings of the blood flow velocity in the CRA in the eyes of patients who had either peripheral and/or cerebrovascular disease, or diabetic vascular problems. We also wanted to present our findings regarding the alteration of this flow by the use of a topical beta-adrenergic receptor blocking agent, timolol maleate, in these two patient groups. The clinical significance of these findings on vision or other aspects of the eye is beyond the scope of this paper. However, a few observations can be made about the flow characteristics in general as well as those in the eye.

In early insulin-dependent (type 1) diabetes an increased blood flow can be found in various organs of the body including the eye,${ }^{9,15-17}$ kidney $^{18}$ and peripheral tissues. ${ }^{9,19,20}$ In the case of the eye the increased flow has the characteristics of flow in inflammatory tissue, with a high peak in the systolic component and an elevated diastolic phase. ${ }^{9}$ The elevation in perfusion may be correlated with glycaemic control and may decrease towards normal if the blood glycaemic levels are reduced. ${ }^{16,21,22}$ The increased flow will cause an increase in capillary pressure unless there is capillary recruitment and/or a fall in post-capillary resistance. ${ }^{21}$ The capillary hypertension is consistent with other physiological data such as an increase in exchangeable sodium, ${ }^{23}$ a reduced tissue oncotic pressure, ${ }^{24}$ an increased transcapillary escape rate of albumin and a controlrelated increase in the capillary filtration coefficient. ${ }^{25}$ What influence these factors may have on the formation of diabetic macular oedema is not clear.

In insulin-dependent diabetes of longer duration there is a limited flow reserve as opposed to the increased perfusion and capillary hypertension in the early phases of the disease. In the kidney, renal plasma flow decreases as the creatinine level starts to rise in diabetic nephropathy. ${ }^{26}$ In the peripheral tissues in insulin-dependent diabetes there is a negative correlation between the duration of the disease and the maximum hyperaemic response to a variety of stimuli. ${ }^{27,28}$ In the eye the preproliferative phase of diabetic retinopathy may be a reaction to the presence of retinal ischaemia. ${ }^{29,30}$ Another recent study suggests that an increase in the retinal blood flow occur in the preproliferative and proliferative phases of diabetic retinopathy. ${ }^{17}$ These changes may be a result of an impaired microvascular responsiveness as suggested by pharmacological studies. ${ }^{31}$

In this study we were interested in two subgroups of insulin-dependent diabetics with different ocular flow velocity characteristics (subgroup A with shortduration diabetes and an increased flow velocity, and subgroup B with longer-standing diabetes and a decreased flow velocity). All these patients had either a normal fundus examination or mild BDR. A correlation was found for the two subgroups between the duration of their diabetes and the peripheral flow characteristics. Subgroup A had diabetes of more recent onset (6.7 years (SD 5)) with an increased peripheral skin flux as measured by laser Doppler flowmetry, while group B had diabetes 
of longer duration (13.5 years (SD 7)) with a generally decreased peripheral skin flux as measured by laser Doppler flowmetry. It must be remembered that other factors may influence the retinal blood flow. Breathing $100 \%$ oxygen, ${ }^{32}$ occlusive peripheral vascular disease, cerebrovascular vascular disease with carotid plaques, essential hypertension ${ }^{11}$ and some systemic vascular diseases such as giant cell arteritis ${ }^{33}$ may cause a reduction in the retinal blood flow. An increased blood glucose level ${ }^{21,22}$ and treatment with medication such as nifedipine or nimodipine $e^{9}$ may cause an increase in the retinal blood flow. This study examined only the influence of topical timolol $0.5 \%$ on the blood flow velocity. In subgroup A the retinal flow velocity was already significantly increased when compared with that in normals and topical timolol did not significantly influence this increased flow. In subgroup B the retinal flow was significantly reduced when compared with that in normals and it did significantly increase after the use of topical timolol but not to the levels obtained in normals. The diastolic component also increased but not as much as it did in normals. In this study the diabetics either had normal fundus examinations or mild BDR, but other diabetics have more advanced disease. Other diabetics with DMO, preproliferative retinopathy or PDR may also have glaucoma and may also be under treatment with topical timolol. If the timolol were to increase the flow velocity in these eyes it could influence the retinopathy. How DMO or PDR may be influenced by an increased flow velocity with topical timolol needs to be evaluated, as does as any effect it may have on visual acuity.

The other group of patients who were studied had peripheral and/or cerebrovascular disease with a decreased retinal blood flow. Some of these patients also had carotid plaques and hypertension, which are also known to reduce the retinal blood flow velocity. ${ }^{11}$ It is also known that treatment with systemic drugs such as nifedipine or nimodipine can increase an already reduced retinal blood flow in this patient group. ${ }^{9}$ Nifedipine, $10 \mathrm{mg}$ three times a day for 2 weeks, in 6 vascular patients with a reduced retinal blood flow, led to a significant increase in the flow. ${ }^{9}$ Nimodipine, $30 \mathrm{mg}$ two times a day for 6 weeks, in 6 patients with an occlusion of the internal carotid artery, had a similar effect. ${ }^{9}$ Since these systemic drugs can increase the retinal blood flow in vascular patients with an already decreased flow, we wanted to know the effect of topical timolol on the blood flow in this group of patients. It was shown that topical timolol maleate $0.5 \%$ significantly increased the blood flow velocity of the CRA in this patient group. The increase, however, was not as large as that in the normals. The diastolic component also increased, but again not as much as it did in the normals. What effect this increase may have on the vision in vascular patients treated with timolol is not known and further study would be needed to evaluate this.

The microcirculation in the body has sympathetic innervation which controls the blood flow. Histochemical studies of the eye using human and animal tissue have shown the absence of adrenergic innervation to the retinal vessels. The rabbit eye is the only exception. ${ }^{34,35}$ Since the retinal vessels appear to be without innervation, it is thought that autoregulation controls retinal blood flow. ${ }^{36}$ There is evidence, however, that other factors may play a role in the regulation of its blood flow. Recent studies have shown that binding sites are present on retinal blood vessels for alpha- and beta-adrenergic agents, cholinergic agents and angiotensin. ${ }^{37-42}$ In future it may be found that some of these binding sites play a role in the chemical mediation of retinal blood flow.

In this study there was a sign:ificant increase in the blood flow velocity of the CRA with the use of topical timolol in three different patient groups: normals, diabetics with a decreased flow and vascular patients with a decreased flow. In the fourth group, diabetics with an increased flow, there was no significant increase. In the three groups with the increased flow there was also an increase in the diastolic component. The diastolic component is a measurement of the peripheral vascular resistance, an increase indicating a decrease in the peripheral vascular resistance. In the case of the eye the increase in the diastolic component means a decrease in the peripheral vascular resistance, which may have led to the subsequent increase in the blood flow velocity. There is also other evidence that may explain a vasodilatory mechanism in the eye leading to the increased flow velocity. A study investigating the contractile responses of bovine retinal microarteries in vitro found a relaxation of the vessel walls to calcium antagonists and to betaantagonists, including timolol and propranolol. ${ }^{43}$ In another study of the porcine long posterior ciliary artery, vascular relaxation was found with the use of betaxolol, carteolol and timolol. ${ }^{44}$ This is further evidence that the increased blood flow velocity measured in the CRA after the use of topical timolol may be partially due to a vasodilatory effect. Timolol lowers the IOP and this may also have an effect on the blood flow velocity. Regardless of the mechanism, this study indicates an increase in the flow velocity in three of the four groups studied. Clinical studies will be needed to evaluate the effect this increased flow velocity may have on the vision in normals, diabetics and vascular patients, as well as the effect it may have on diabetic retinopathy. In particular it will be important to know how DMO and PDR are affected by this increased flow velocity. 
The authors wish to thank the volunteers from St Mary's Hospital Medical School and the Pierangeli Clinic without whom this study would not have been possible. This study was paid for by the authors.

Key words: Central retinal artery, Diabetic microangiopathy, Doppler ultrasonography, Duplex scanner, Timolol maleate, Vascular disease.

\section{REFERENCES}

1. Katz IM, Hubbard WA, Getson AJ, Gould AL. Intraocular pressure decrease in normal volunteers following timolol ophthalmic solution. Invest Ophthalmol Vis Sci 1976;15:489-92.

2. Zimmerman TJ, Kaufman HE. Timolol, a betaadrenergic blocking agent for the treatment of glaucoma. Arch Ophthalmol 1977;95:601-4.

3. Zimmerman TJ, Kaufman HE. Timolol: dose response and duration of action. Arch Ophthalmol 1977;95:6057.

4. Radius R, Diamond G, Pollak I, Langham ME. Timolol: a new drug for the management of chronic simple glaucoma. Arch Ophthalmol 1978;96:1003-8.

5. Wilson RP, Kanal N, Spaeth GL. Timolol: its effectiveness in different types of glaucoma. Ophthalmology 1979;86:43-50.

6. Coakes RL, Brubaker RF. The mechanism of timolol in lowering intraocular pressure. Arch Ophthalmol 1978;96:2045-8.

7. Grunwald JE. Effect of topical timolol on the human retinal circulation. Invest Ophthalmol Vis Sci 1986;27:1713-9.

8. Grunwald JE. Effect of timolol maleate in the retinal circulation of human eyes with ocular hypertension. Invest Ophthalmol Vis Sci 1990;31:521-6.

9. Belcaro G, Steigerwalt RD Jr, Laurora G, Cesarone MR, Marelli C. Valutazione del flusso nella arteria e nella vena centrale della retina con Duplex scanning ad alta risoluzione. Minerva Angiol 1989;14:175-80.

10. Steigerwalt RD Jr, Belcaro G, Cesarone MR, Laurora G, De Sanctis MT, Milazzo M. Doppler ultrasonography of the central retinal artery in normals treated with topical timolol. Eye 1993;7:403-6.

11. Cesarone MR, Laurora G, Steigerwalt RD, Belcaro G. Retinal Duplex scanning in cerebrovascular disease and hypertension. Vasa 1992;21:163-6.

12. Shore AC, Tooke JE. Assessment of diabetic microangiopathy. In: Belcaro GV, Hoffmann U, Bollinger A, Nicolaides AN, editors. Laser doppler. London: MedOrion, 1994;119-28.

13. Belcaro G, Vasdekis S, Rulo A, Nicolaides AN. Evaluation of skin blood flow and venoarteriolar response in patients with diabetes and peripheral vascular disease by laser Doppler flowmetry. Angiology 1989;40:953-7.

14. Beider EE, Hoffmann U, Franzeck UK, Bollinger A. Digital systolic blood pressure measured by the laser Doppler technique in peripheral ischaemia. In: Belcaro GV, Hoffmann U, Bollinger A, Nicolaides AN, editors. Laser doppler. London: Med-Orion, 1994:63-72.

15. Kohner EM, Hamilton AM, Saunders SJ, Sutcliffe BA, Bulpitt CJ. The retinal blood flow in diabetes. Diabetologia 1975;11:27-33.

16. Grunwald JE, Riva CE, Baine J, Bruckner AJ. Total retinal volumetric flow rate in diabetic patients with poor glycaemic control. Invest Ophthalmol Vis Sci 1992;23:356-63.

17. Patel V, Rassam SMB, Newsom RSB, Wiek J, Kohner
EM. Retinal blood flow in diabetic retinopathy. BMJ 1992;305:678-83.

18. Christiansen JS, Gammelgaard J, Tronier B, Svendsen $\mathrm{PA}$, Parving $\mathrm{H}-\mathrm{H}$. Kidney function and size in diabetics, before and during initial insulin treatment. Kidney Int 1982;21:683-8.

19. Gundersen HJG. Peripheral blood flow and metabolic control in juvenile diabetes. Diabetologia 1974; 10:225-31.

20. Tooke JE. Microvascular haemodynamics in diabetes. Eye 1993;7:227-9.

21. Tooke JE. Microvascular haemodynamics in diabetes mellitus. Clin Sci 1986;70:119-25.

22. Kohner EM. The effect of diabetic control on diabetic retinopathy. Eye 1993;7:309-11.

23. O'Hare JA, Ferniss J, Twomey B, O'Sullivan JD Essential hypertension and hypertension in diabetic patients without nephropathy. J Hypertens 1983; 1(Suppl 2):200-3.

24. Fauchald P, Norseth J, Jervell J. Transcapillary colloid osmotic gradient, plasma volume and interstitial fluid volume in long term type 1 (insulin-dependent) diabetes. Diabetologia 1985;28:269-73.

25. Parving H-H, Noer I, Deckert T, Evrin P-E, et al. The effect of metabolic regulation on microvascular permeability to small and large molecules in short term juvenile diabetics. Diabetologia 1976;12:161-6.

26. Mogensen CF, Christensen CK, Vittinghus E. The stages in diabetic renal disease. Diabetes 1983;32 (Suppl 2):64-78.

27. Rayman G, Williams SA, Spencer PD, Smaje LH, Wise $\mathrm{PH}$, Tooke JE. Impaired microvascular hyperaemic response to minor skin trauma in type 1 diabetes. BMJ 1986;292:1295-8.

28. Shore AC, Price KJ, Sandeman DD, Green EM, Tripp $\mathrm{JH}$, Tooke JE. Impaired microvascular hyperaemia in children with diabetes mellitus. Diabetic Med 1991;8:619-23.

29. Bresnick GH, de Venecia G, Myers EL, Harris JA, Davis MD. Retinal ischaemia in diabetic retinopathy. Arch Ophthalmol 1975;93:1300-10.

30. Grunwald JE, Riva CE. Retinal blood flow in diabetes. In: Belcaro GV, Hoffmann U, Bollinger A, Nicolaides AN, editors. Laser doppler. London: Med-Orion, 1994:233-47.

31. Boolell M, Tooke JE. The skin hyperaemic response to local injection of substance $P$ and capsaicin in diabetes mellitus. Diabetic Med 1990;7:898-901.

32. Grunwald JE, Riva CE, Brucker AS, Sinclair SH, Petrig BL. Altered retinal vascular response to $100 \%$ oxygen breathing in diabetes mellitus. Ophthalmology 1984;91:1447-52.

33. Steigerwalt RD Jr, Cesarone MR, Laurora G, Belcaro G, De Sanctis MT, Incandela L, Christopoulos V. Doppler ultrasonography in giant cell arteritis. Int Angiol 1994;13:286-9.

34. Laties AM. Central retinal artery innervation: absence of adrenergic innervation to the intraocular branches. Arch Ophthalmol 1967;77:405-9.

35. Ye X, Laties AM, Stone RA. Peptidergic innervation of the retinal vasculature and optic nerve head. Invest Ophthalmol Vis Sci 1990;31:1731-7.

36. Anderson DR. Anatomy and physiology of the ocular blood flow. In: Lambrou GN, Greve EL, editors. Ocular blood flow in glaucoma, Amsterdam: Kugler and Ghedini, 1989:55-9.

37. Rockwood EJ, Fantes F, Davis EB, Anderson DR. The response of retinal vasculature to angiotensin. Invest Ophthalmol Vis Sci 1987;28:676-82. 
38. Forster BA, Ferrari-Dileo G, Anderson DR. Adrenergic alpha-1 and alpha-2 binding sites are present in bovine retinal blood vessels. Invest Ophthalmol Vis Sci 1987;28:1741-6.

39. Ferrari-Dileo G, Davis EB, Anderson DR. Angiotensin binding sites in bovine and human retinal blood vessels. Invest Ophthalmol Vis Sci 1987;28:1747-51.

40. Ferrari-Dileo G, Ryan JW, Rockwood EJ, Davis EB, Anderson DR. Angiotensin-converting enzyme in bovine, feline and human ocular tissues. Invest Ophthalmol Vis Sci 1988;29:876-81.

41. Ferrari-Dileo G. Beta-1 and beta-2 adrenergic binding sites in bovine retina and retinal blood vessels. Invest Ophthalmol Vis Sci 1988;29:695-9.
42. Ferrari-Dileo G, Davis EB, Anderson DR. Biochemical evidence for cholinergic activity in retinal blood vessels. Invest Ophthalmol Vis Sci 1989;30: 473-7.

43. Hoste AM, Boels PJ, Andries LJ, Brutsaert DL, De Laey JJ. Effects of beta-antagonists on contraction of bovine retinal microarteries in vitro. Invest Ophthalmol Vis Sci 1990;31:1231-7.

44. Hester RK, Chen Z, Becker EJ, McLaughlin M, DeSantis L. The direct vascular relaxing action of betaxolol, carteolol and timolol in porcine long posterior ciliary artery. Surv Ophthalmol 1994;Suppl $38: 125-34$ 